\title{
Yüzey Modifikasyonu Yapılmış Isırgan Otu Lifi Takviyeli Polyester Kompozit Üretimi ve Mekanik Özellikleri
}

\author{
Emel Ceyhun SABIR*1 \\ ${ }^{1}$ Çukurova Üniversitesi, Mühendislik Fakültesi, Tekstil Mühendisliği Bölümü, Adana
}

$\ddot{\mathbf{O z}}$

Geliş tarihi: 04.11.2019 Kabul tarihi: 30.07 .2020

Bu çalışmada, bir tekstil lifi olarak bilinen 1sırgan otu lifi takviyeli polyester kompozit malzeme üretilmiş ve malzemenin mekanik özellikleri araştırılmıştır. Isırgan otu elyafının yüzeyi $\% 1, \% 3, \% 5$ ve $\% 10$ dört farklı oranda $\mathrm{NaOH}$ alkali işlemle aşındırılmıştır. Elyafın matrise takviye oranı sabit tutulmuş olup, \%30 oranındadır. Lifler boyu yönde taranmış ve şerit formunda kompozit içerisine yerleştirilmiştir. Kompozit malzemeler plakalar halinde RTM teknolojisi ile üretilmiştir. Takviye elemanının kompozitin Çekme dayanımı, 3 nokta eğilme dayanımı ve darbe dayanımına etkileri araştııılmıştır. Isırgan elyafına uygulama alkali işlemin $(\mathrm{NaOH})$ çekme dayanımı düşürdüğü ancak eğme ve darbe dayanımını iyileştirdiği görülmüştür. Çalışma, 1sırgan otunun elyaf formunda \%30 oranında kompozit malzemede takviye elemanı olarak kullanılabileceğini ortaya koymuştur.

Anahtar Kelimeler: Kompozit, Isırgan otu lifi, Yüzey değişikliği, Mekanik özellikler, Polyester reçine

\section{Production and Mechanical Properties of Surface Modified Nettle Fiber Reinforced Polyester Composite}

\begin{abstract}
In this study nettle fiber which known as a textile fiber reinforced polyester composite material was produced and the mechanical properties of the material were investigated. The surface of the nettle fiber was abraded by $1 \%, 3 \%, 5 \%$ and $10 \% \mathrm{NaOH}$ in four different ratios. The reinforcement ratio of the fiber to the matrix is kept constant and $30 \%$. The fibers were scanned in the longitudinal direction and placed in the ribbon-shaped composite. Composite materials are produced with plates as RTM technology. Tensile strength of the reinforcement element, 3-point bending strength and impact strength were investigated. It has been observed that the alkali treatment $(\mathrm{NaOH})$ applied to nettle fiber reduces the tensile strength but improves the bending and impact strength. The study has been shown that stinging nettle fiber can be used as a reinforcing composite material.
\end{abstract}

Keywords: Composite, Nettle fiber, Surface modification, Mechanical properties, Polyester resin

\footnotetext{
*Sorumlu yazar (Corresponding author): Emel Ceyhun SABIR,emelc@cu.edu.tr
} 


\section{GíRiş̧}

Kompozit malzemeler, gerek mekanik özelliklerinin üstünlüğ̈ olması ve gerekse hafif olması nedeniyle teknolojik olarak üstün ve dayanıklı malzemelerdir. Kompozit birden çok bileşenden oluşan kompleks bir yapıdır. Kompozit malzeme mekanik avantajlarının yanı sıra üretim tekniklerinden dolayı genel olarak ucuz bir malzeme türü değildir. Kompozit en genel haliyle takviye elemanı (lif, kumaş vb. gibi) ve yapıştırıcı elemandan (matris) oluşur. Matris, lifleri bir arada tutan, kayma güçlerini yayan, kaplama olarak işlev gören [1] ve özellikleri sıcaklığa göre değişen termoset (polyester, vinilester, epoksi, poliüretan, fenolik) veya termoplastik (polietilen, polipropilen, polistiren) reçinelerdir. Lif takviyeli kompozitlerde lifler; yapıya sertlik, dayanım, termal stabilite ve diğer yapısal özellikleri kazandıran yapısal bir birimdir [2]. Geleneksel kompozitlerde takviye elemanı olarak yapıya yüksek mukavemet ve modül değerleri kazandıran cam, aramid, kevlar ve karbon gibi yüksek performanslı lifler tercih edilmektedir [3]. Son yıllarda, polimer matrislere cam lifi dışında güçlendirici olarak doğal liflerin kullanımına yönelik çalışmalarda artışlar görülmektedir. Doğal liflerin ucuz, hafif, kolay elde edilebilir olması takviye özelliklerinin araştırılmasında en önemli nedenlerdir. Doğal lifler takviye malzemesi olarak, toz, kısa lif, liften mamul iplik ve iplikten dokunmuş kumaş şekillerinde kullanılabilmektedir. Bir kompozit malzemenin özelliğini genel olarak lif özellikleri, reçine özellikleri, kompozitteki lif-reçine oranı, kompozitteki lif geometrisi ve yerleşimleri [3], lifmatris çekimi ve ara yüzdeki yük transferi [4] gibi parametrelerin belirlediği düşünülmektedir. Kompozite takviye özelliği taşıyan doğal lifte beklenen en önemli iki özellik, kopma uzamasının ve nem alma kapasitesinin (hidrofilite) düşük olmasıdır. Doğal liflerle ilgili kompozit üründeki en istenmeyen özellik hidrofilik olmalarıdır [5,6].

Doğal liflerin takviye elemanı olarak kullanımına yönelik çalışmalar pek çoktur. $\mathrm{Bu}$ çalışmada 1sırgan otu lifinden kompozit malzeme üretimi araştırılmıştır. Avrupa'da bir tekstil hammaddesi olarak 1sırgan otu lifi kullanımı, pamuktan bile öncedir [7]. Isırgan otu lifi, pamuktan daha mukavemetli ve ketenden ise daha incedir. Bu lifler, sulama ve zirai ilaç bakımından pamuktan daha çevre dostudur. Isırgan lifinin iki türüne kompozit üretiminde çok rastlanır. Bunlardan birisi European nettle Urtica dioica ve diğeri Himalayan nettle Girardinia diversifoli'dur [8,9]. Çizelge 1, Elyaf mekanik özelllikleri açısından kompozit kullanılan doğal lifleri karşılaştırmaktadır.

Çizelge 1. Seçilmiş doğal liflerin kompozit malzeme için önemli özellikleri [8]

\begin{tabular}{|l|c|c|c|c|c|c|}
\hline Elyaf özellikleri & E-cam & Keten & Kenevir & Jüt & Kenaf & Isırgan otu \\
\hline Yoğunluk kg/m ${ }^{3}(\rho)$ & 2550 & 1530 & 1520 & 1520 & 1193 & - \\
\hline Elastisite modülü $(\mathrm{GPa})$ & 71 & 58 & 70 & 60 & $14-38$ & $87 \pm 28$ \\
\hline Çekme dayanımı $(\mathrm{MPa})$ & 3400 & 1339 & 920 & 860 & 240 & 1594 \\
\hline Özgül modül $(E / 1000 \rho)$ & 28 & 38 & 46 & 39 & $12-32$ & - \\
\hline Kopma uzamas1 $(\%)$ & 3,4 & 3,27 & 1,7 & 2 & - & 2,11 \\
\hline Nem alma $(\%)$ & - & 7 & 8 & 12 & - & - \\
\hline
\end{tabular}

Isırgan otu lifi ile ilgi geçmişten bu yana yapılan çalışmalar vardır. Bacci ve arkadaşları [10]'na göre 1sırgan lifleri çapta, lignin içeriğinde ve uzamada kenevir liflerine ve gerilme dayanımında ise keten ve pamuğa benzetmişlerdir. Sap bölümleri arasında bulunan farklı fizikselmekaniksel özellikler dikkate alındığında sapların yukarı kısımlarının tekstil endüstrisi için kullanılabileceği düşünülmüştür. Isırgan lifinin yoğunluğu $0,72 \mathrm{~g} / \mathrm{cm}^{3}$, dir. $\mathrm{Bu}$ yoğunluk değeri kenevir, pamuk ve diğer liflere göre oldukça düşüktür ve bu daha hafif ürünleri mümkün kılmaktadır. Bacci ve arkadaşları [11] kimyasal havuzlama, suda havuzlama, mikrobiyolojik ve 
enzimatik metotları ile 1sirgan otu lifini elde etmeye çalışmışlardır. Tüm saplar ve mekanik olarak ayrıştırılmış liflerin mikrobiyolojik havuzlanması ile suda havuzlamadan daha yüksek kalitede lifleri üretmiştir. Huang [12] 1sırgan lifinin uzunluk, incelik, gerilme dayanımı ve nem absorbsiyon yeteneğini araştırmıştır. Araştırmalar 1sırgan liflerinin çoğunun 20-70 mm uzunluk ve 15-40 mikron incelik aralığında, yün, pamuk ve diğer pek çok gövde lifi ile karşılaştırıldığında nem emme yeteneklerinin özel lif yapısından dolayı daha yüksek olduğunu ve sıklıkla kullanılan doğal liflerin yerine kullanılabileceğini göstermiştir. $\mathrm{Bu}$ özellik tekstil materyali olarak iyi bir özellik olsa da kompozit malzeme için olumlu bir özellik değildir. Eğirme denemeleri saf 1sırganın pürüzsüz yüzeyi ve düz yapısından dolayı saf ısırgan lifi ile iplik üretmenin pratikte mümkün olmadığını göstermiştir. Fakat diğer uygun lifler ile karışım ipliklerinin eğrilebileceği sonucu çıkarılmıştır. Bodros ve Baley [13] 1sırgan liflerinin ilgi çekici gerilme özelliklerine sahip olduğunu ve kompozit malzemelerde takviye bileşeni olarak kullanılabileceğini göstermek istemişlerdir. Cam lifi ile karşılaştırıldığında ısırgan liflerinin daha sert olduğu ortaya çıkarılmıştır.

Paukszta ve arkadaşları [14], polipropilen matrisli 1sırgan otu (urtica duocia) takviyeli kompoziti ekstrüzyon metodu ile üretmişleridir. Isırgan otu lifinin PP matris içinde güçlü özellikler gösterdiğini bulmuşlardır. Bajpai ve arkadaşları [15] ise 1sırgan otu-polipropilen kompozitin soğuk, günışığ1, yağ, nehir suyu ve toprak gibi çeşitli çevre koşulları karşısında gerilme dayanımlarını araştırmışlardır. En büyük etkinin günışı̆ğ ve nehir suyunda olduğunu, en az etkilenmenin ise toprakta olduğunu bulmuşlardır.

Merila [16] 1sırgan otu lifi takviyeli epoksi ve fenolik kompozitlerin mekanik özelliklerini incelemiştir. Isırgan otu lifleri tek yönlü, herhangi bir modifikasyon işlemi uygulanmadan kompozitte kullanılmıştır. Ağırlıkça \%24 1sırgan otu lifi takviyeli epoksi kompozitlerinin gerilme dayanım ve sertliği, ağırlıkça \%21 keten lifi takviyeli epoksi kompozitlerinin gerilme dayanımı ve sertliğinin yaklaşık yarısı kadar değerler vermiştir. Ağırlıkça $\% 23$ 1sırgan otu lifi takviyeli fenol kompoziti saf epoksiden daha düşük gerilme dayanımı ve sertlik değeri vermiştir. Mikroskobik araştırmalar lifmatris arası çekimin fenolün epoksiye göre daha iyi olduğunu göstermiştir. Fischer ve arkadaşları [17] \%20, 30, 40 ağırlık oranında ısırgan otu lifi takviyeli polilaktikasit (PLA) ve \%30 ağırlık oranında 1sırgan otu lifi takviyeli polipropilen kompozitlerini lif modifikasyonu yapmadan, liflerin boyuna yönde hizalanması suretiyle elde etmiştir. En fazla takviye etkisini \%30 ağırlık oranını ile boyuna yönde 1sırgan otu-PLA kompozitleri (\%60'lık bir etki) göstermiştir. Eğilme modülü için tüm 1sırgan otu-PLA kompozitleri takviye etkisi göstermiştir. Bajpai ve arkadaşları [18], PLA ve Polipropilen matrislerle sisal ve 1sırgan otu lifi ipliklerinden dokunmuş kumaşlarla takviye edilmiş kompozitlerin mekanik özelliklerini karşılaştırmışlardır.

Doğal lif takviyeli kompozitlerde ara yüzey modifikasyonları yapılarak elde edilecek kompozitlerin performans özelliklerini geliştirmeyi amaçlayan çalışmalar da literatürde yer almaktadır [19-33]. Karaduman [34]'a göre, ' $\mathrm{NaOH}$ ile alkali işlem ekonomik ve etkili olması bakımından doğal lif kompozitlerinin ara yüz modifikasyonunda çok yaygın olarak kullanıldığını göstermiştir. Alkali işlemle lif yüzeyindeki yağlar, hemiselüloz ve pektinin tamamı ile ligninin bir kısmı uzaklaşarak daha pürüzlü ve fibrilli bir lif yüzeyi elde edilir Dolayısıyla matris maddesi ile mekanik bağlanma için lifin toplam yüzey alanı artar. $\mathrm{Bu}$ da adhezyonu ve lif-matris ara yüzünün kalitesini arttırır". Isırgan otu lifinin elde edilme koşulları ve 1sırgan otu liflerinden elde edilebilecek ürünlerle ilgili bilgi olmakla beraber, ara yüzey modifikasyonu yapılarak isırgan otu lifi takviyeli kompozit üretimiyle ilgili çalışmaya rastlanmamıştır veya kısıtlıdır. Yüzey modifikasyonu yapılmamış ısırgan otu lifinin, matrise, boyuna yönde yerleştirilmesinin kompozitin mekanik özellikleri iyileştirdiği ortaya konulmuştur [17]. $\mathrm{Bu}$ çalışmada yüzey modifikasyonu yapılmış ve yapılmamış şeklinde ısırgan otu lifi takviye olarak kullanılmıştır. 


\section{MATERYAL VE YÖNTEM}

\subsection{Materyal}

Çalışmada takviye malzemesi olarak ısırgan otu lifi kullanılmıştır. Kullanılan ısırgan otu lifi, Nepal menşeilidir. Projede kompozit matris elemanı olarak polyester reçinenin kullanılmasına karar verilmiştir. Polyester reçine Polipol 336 kodlu olup Poliya A.Ş./Türkiye firmasından temin edilmiştir. Kalıp ayırıcı olarak yine Poliya A.Ş.'den Polivaks alınmıştır.

\subsection{Metot}

\subsubsection{Isırgan Otu Yüzey Modifikasyonu}

Doğal liflerin matrisle daha iyi bir birleşme sağlaması amaciyla yüzey modifikasyonu işlemleri uygulanabilmektedir. Isırgan otu elyafı takviyeli kompozit malzeme üretimi için öncelikli olarak ısırgan otu elyafina alkali uygulanmasına karar verilmiştir. $\mathrm{Bu}$ işlemle 1sırgan otu liflerinin de kimyasal işlemler ile matris malzemeye karşı olan uyumluluğunun artırılması ile güçlü bir takviye etkisi oluşturacağı düşünülmektedir. Çalışmada, 1sırgan otu lifine yüzey modifikasyon işlemleri içerisinde gerek etkili olması ve gerekse ucuz olması nedeniyle siklıkla kostik soda, $\mathrm{NaOH}$, alkali işlem kullanılmaktadır.

Literatürde farklı oranlarda uygulanabildiği görülmekle beraber bu oran genellikle \%0-10 arasında değişmektedir. Bu çalışmada, $\mathrm{NaOH}, \% 3$, $\% 5$ ve $\% 10$ oranlarında seçilmiştir. Buna göre 1sırgan otu lifi, yüzey işlemi görmemiş ve yüzeyi alkali işlemle $(\mathrm{NaOH})$ pürüzleştirilmiş şekilde kullanılmıştır. Bu numune lifler üzerindeki yağ ve kirlerin uzaklaştırılması için ön işlem olarak yıkama yapılmıştır (Yıkama ve Kuru Temizleme Haslık Makinesi ve Tüpleri, Gyrowash). Yapılan işlemlerde 1sırgan otu lif numuneler için ağırlıklar 5 g olarak belirlenmiştir. Yıkamada \%2 noniyonik deterjanla y1kama tüplerinde saf su ile $60{ }^{\circ} \mathrm{C}$ 'de 1 saat yıkama işlemi yapılmıştır. Yıkanan lifler saf su ile durulanmıştır. Lif tutamları hiç su damlatmayacak şekilde el ile sıkılmış ve elyaf örneklerinin ıslak ağırlıkları kaydedilmiştir. Son olarak elyaf örnekleri $80{ }^{\circ} \mathrm{C}$ 'deki etüvde $80 \mathrm{dk}$ kurutulmuştur. Kuru elyaf ağırlıkları kaydedildi. Ön izlenim vermesi açısından yıkanmış ve kurutulmuş bir adet 1sırgan otu elyaf numunesi oda sıcaklığında \%1 alkali çözeltisinde $0 . \mathrm{dk}, 10$. dk, 20. dk, 30. dk, 40. dk, 50. dk ve 60. dk işlem gördükten sonra elyafların mikroskobik kesit ve yüzey görüntüleri incelenmiştir (Şekil 1). İşlem süresinin beklendiği gibi elyaf yüzey pürüzlülüğünü zamanla artırdığı gözlemlenmiştir. Kurutulmuş elyaf numuneleri oda sicaklığında, $\% 3, \% 5$ ve $\% 10$ olmak üzere 3 farklı alkali konsantrasyonda, 1 saat bekletilmiştir. İşlem sonunda elyaf numuneleri $\% 2$ seyreltik asetik asit çözeltisi ile nötralize edilmiştir. Lifler üzerinde bulunan alkali atıklar uzaklaşana kadar saf su ile yıkama işlemi yapılmıştır. Yıkanan elyaf numuneleri $80{ }^{\circ} \mathrm{C}^{\prime}$ 'deki etüvde 80 'dk süreyle kurutulmuştur. Ön işleme tabi tutulmuş isırgan otu elyafı numuneleri numune şerit hazırlama makinesinde (Microsdust Trash Analyzer MDTA3/Bossa A.Ş./Adana/Turkey) şerit haline getirilmiştir. Elyaf numuneleri arasında bulunan yabancı maddeler bu aşamada ayrıştırılmış ve lifler paralelleştirilmiştir.

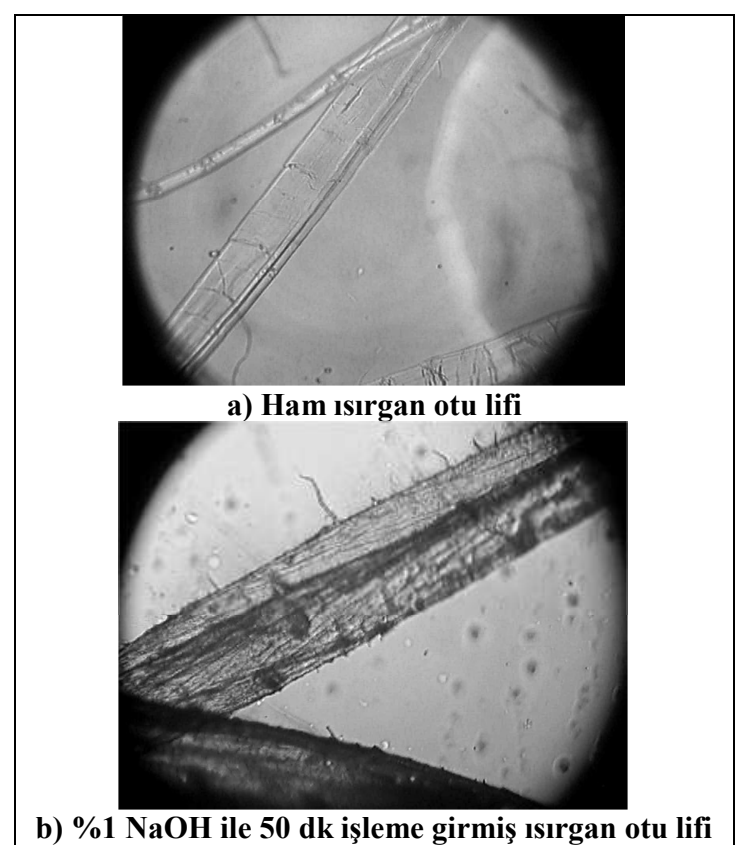

Şekil 1. (a) Alkali işlemsiz (b) $\mathrm{NaOH}$ alkali işlemli, 1sırgan otu lifine ait mikroskop görüntüleri (x500) 


\subsubsection{Kompozit Plaka Üretimi}

Kompozit malzeme içerisinde takviye elemanının ağırlıç̧a hangi oranda kullanılacağı da araştırma konularındandır. Doğal lifli takviyeli kompozit çalışmalarında ağırlıklı olarak \%30 takviye malzemesi kullanımının yaygın olduğu görülmüştür. $\mathrm{Bu}$ nedenle çalışmada 1sırgan otu lifinin kompozit içerisinde \%30 oranında kullanılmasına karar verilmiştir. $\mathrm{NaOH}$ çözeltisi ile işleme girmiş liflerden oluşan her lif numunesi \%30 oranında takviye oranında polyester reçineye uygulanmış ve başarılı şekilde kompozit üretilebilmiştir. Lifler belirlenen kalıba yerleştirilmeden önce oluşacak kompozit plakanın kalıptan kolay ayrılması için jelkot kullanılmıştır. Hava kabarcığı oluşumunu önlemek (çatlak oluşumunu engelleyecektir) ve reçinenin homojen dağılımını sağlamak için bir rulo yardımıyla reçinenin bütün liflere yayılması sağlanmıştır. Üretim yöntemi olarak RTM teknolojisi kullanılmıştır (Şekil 2). Burada polyester $100 \mathrm{~g}$, Kobalt 0,03 g ve MEKP kalıp ayırıcı $2 \mathrm{~g}$ olarak kullanılmıştır. Isırgan otu lifinin şerit hali Şekil 2a'da, kullanılan kalıp Şekil 2b'de görülmektedir. Kalıp alt ve üst şeklinde iki parçadan oluşmakta olup şerit 1sırgan otu elyaf (Şekil 2a) ve reçine bu kalıp içerisine yerleştirilmektedir. Kompozit plaka soğuk preste 8 saat bekletilmiş ve Şekil 2d'de görüldüğü şekilde elde edilmiştir.
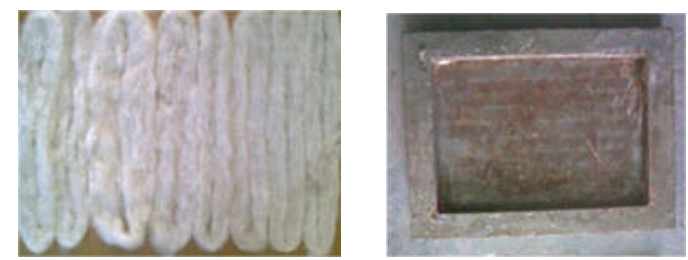

a) Taranmış şerit elyaf
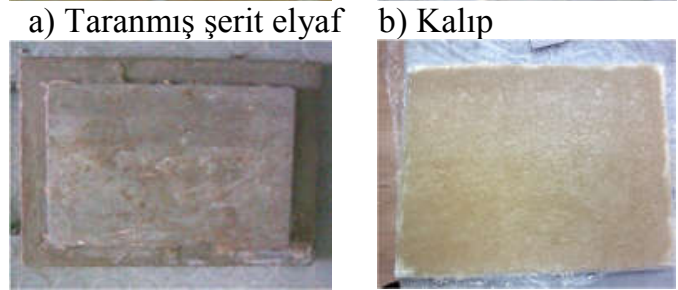

c) Kalıba elyaf yatırma

\subsubsection{Mekanik Testler}

Üretilen kompozit plakalara 3 adet mekanik test uygulanmıştır. Çekme Dayanımı Testi, ASTM D 638 standardına göre yapılmaktadır. Çekme Hızı $5 \mathrm{~mm} / \mathrm{dk}$ ve çeneler arası mesafe $115 \mathrm{~mm}$ alınmıştır (Zwick/Roell Z010). 3 nokta Eğilme (eğme) Dayanımı Testi, ASTM D 790 standardına göre yapılmıştır (Zwick/Roell Z010). İzod Çentikli Darbe Dayanım Testi ise ASTM D 256 standardına göre yapılmıştır (Zwick/Roell HIT 5,5, Salınım Açısı 148). Tüm testlerde ortam sıcaklığı $21{ }^{\circ} \mathrm{C}$ 'dir.

\section{ARASTTIRMA BULGULARI}

\subsection{Isırgan Otu Elyafı ile İlgili Bulgular}

Isırgan otu, Kompozit malzemenin takviye bileşenidir. Kompozit içerisindeki oranı ağırlıça $\% 30$ 'dur. Isırgan otu lifini takviye malzemesi olarak kullanırken 4 farklı örnek oluşturulmuştur. $\mathrm{Bu}$ örneklerden ilki ısırgan otu lifinin yüzeyinin herhangi bir işlem görmemiş halidir ve referans numunedir. Bunun dişında $\% 3, \% 5$ ve $\% 10$ şeklinde 4 farklı yüzey modifikasyonu işlemi uygulanmıştır. İşlemsiz ve yüzeyi pürüzleştirilen ısırgan otu elyafının SEM görüntüleri lifin enine ve boyuna kesitleri için alınmıştır. Şekil 3, işlem görmemiş enine ve boyuna 1sirgan otu lif görüntülerini göstermektedir. Lifin mikroskobik görüntülerine bakıldığında $\mathrm{NaOH}$ alkali işlemin lif kesitinde ciddi modifikasyona neden olduğu görülmüştür. Özellikle enine kesit görüntülerinde lifin katmanlara ayrıldığı, bütünlüğünün bozulduğu gözlenmiştir. Boyuna lif görüntülerinde en dikkat çeken kısım gövdeden ayrılan fibril lifli yapılardır. $\mathrm{NaOH}$ işleminin lif üzerindeki aşındırıcı etkisi görülebilmiş olup bu çalışmanın ana hedeflerinden birisidir. Yüzey aşındırma işleminin deneyde uygulanan $\mathrm{NaOH}$ işlemleri ile sağlanabildiği görülmüştür.

Şekil 2. Kompozit plaka yapımında kullanılan kalıp (2 parça) ve üretilen kompozit plaka 


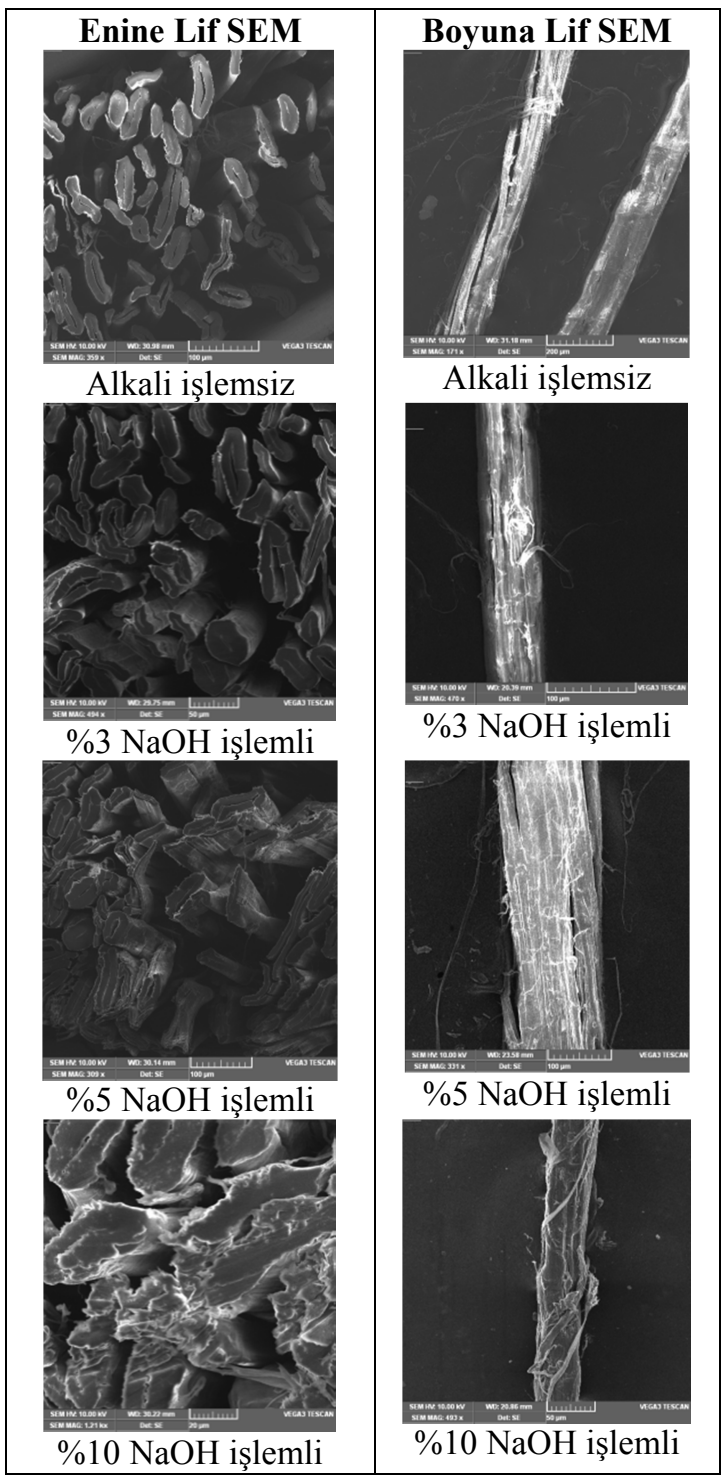

Şekil 3. Farklı konsantrasyonlarda $\mathrm{NaOH}$ Alkali işlemi uygulanmış ısırgan otu lifinin enine ve boyuna kesit SEM görüntüleri

\subsection{Mekanik Özelliklere ait Bulgular ve Değerlendirme}

Kompozit malzemelerde elastisite modülü (E-Modül) çok önemlidir. Saf polyester de dahil olmak üzere E-Modül karşılaştırması için Şekil 4 incelenebilir. Burada öncelikle 1sirgan otu takviyesinin saf polyesterin E-modülüne katkı sağladığı görülmektedir. Tespit edilen E-Modül, cam lifi destekli kompozitlere göre daha düşüktür. Ancak, yine de 1sirgan otu lifleri takviye etkisi gösterebilmiştir. Şekilden \%5 işlem görmüş ısırgan otu lifli kompozitin en yüksek E-Modüle sahip olduğu görülmektedir. Yüzey işlemi uygulanmadığında E-Modül'de kayda değer bir artış görülmemiştir.

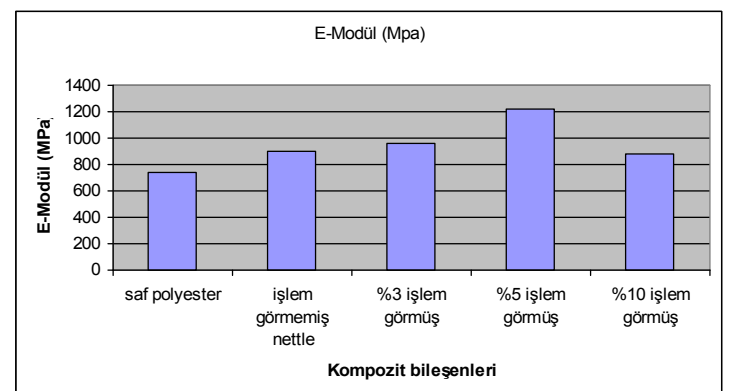

Şekil 4. Kompozit plakaların elastisite modülü

Kompozit malzemelerin mekanik özellikleri içerisinde en önemli yeri Çekme dayanımı alır. Saf Polyester ile kompozitlerin çekme dayanımı karşılaştırması Şekil 5'den görülebilir. Burada 1sırgan otu takviyesinin saf polyesterin çekme dayanımını artırdığ 1 görülmektedir. Isırgan otu içeren kompozitler içerisinde işlem görmemiş ve sonrasında da \%5 işlem görmüş 1sırgan otu lifli kompozitin en yüksek çekme dayanımına sahip olduğu fark edilmektedir.

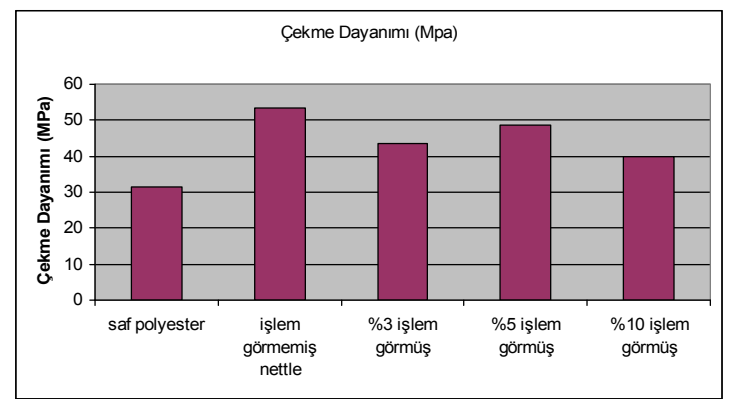

Şekil 5. Kompozit plakaların çekme dayanımı

\% kopma uzaması kompozit malzemeler için öncelikle bakılan bir test olmasa da boyutsal kararlılık ve rijitlik ölçüsü için önemlidir. Burada Şekil 6'da kopma uzamasında da işlem görmemiş 
1sırgan otu lifi destekli kompozit yüksek kopma uzamasına sahip olarak görülmüştür.

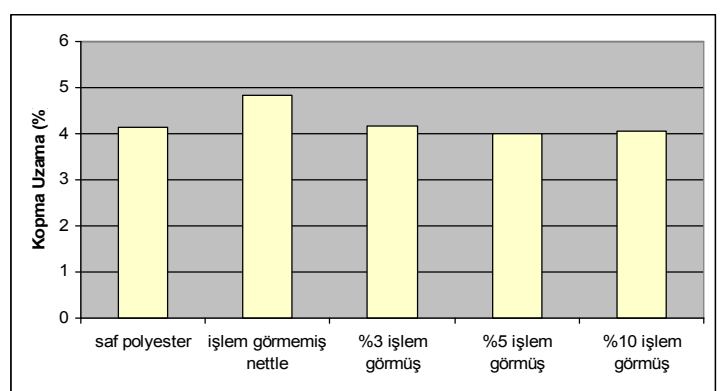

Şekil 6. Kompozit plakaların \% kopma uzaması

Kompozit malzemelerin mekanik özelliklerinden olan eğilme dayanımı, özellikle lif takviyeli kompozitlerde incelenmektedir. Saf polyester plaka ile kompozit plakaların eğilme dayanımı karşılaştırması Şekil 7'den görülebilir. Burada 1sırgan otu takviyesinin saf polyesterin eğilme dayanımını dikkate değer ölçüde artırdığ 1 görülmektedir. Isırgan otu içeren kompozitler içerisinde tüm ısırgan numuneleri birbirine yakın ve yüksek katkı yapmıştır. Lifler boyuna yerleştirilmesinin bu katkıda etkili olduğu söylenebilir.

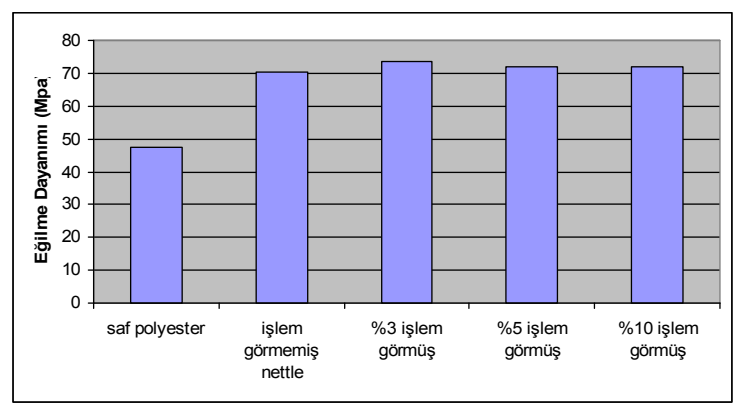

Şekil 7. Kompozit plakaların eğilme dayanımı

Kompozit malzemelerin mekanik özelliklerinden bir diğeri de darbe dayanımıdır. Darbeye karşı direnç kompozit malzemenin tokluğunu ve eksene dik yüklere dayanımını gösterir. Darbe deneyinde, numunenin dinamik bir zorlama altında kırılması için gereken enerji miktarı tayin edilir. Şekil 8, darbe direncini tüm plakalar için göstermektedir. Her ne kadar lifler kesikli ve taranmış halde olsa $\mathrm{da}$, birbirinden bağımsız halde reçineye yerleştirilmiş ise de saf polyester malzemeye göre oldukça iyi darbe dayanımı değerleri elde edilmiştir. Tüm 1sırgan otu lifi destekli kompozit plakalarda doğal lif, takviye görevini yerine getirebilmiştir. Kompozit numuneler içinde darbe dayanımı en iyi olan bileşim işlem görmemiş lif numunesi ile $\% 10$ alkali işlem görmüş lifli numunedir. $\mathrm{Bu}$ iki sonuç birbiri ile çelişiyor gibi görünmektedir. Çünkü işlem görmemiş 1sırgan otu doğal saf kendi halinde liftir. \%10 alkali işlem görmüş olan ise en fazla deformasyona uğratılmış lif grubudur. \%10 alkali işlem görmüş liflerin kesit görünüşleri önceki bölümlerde incelenmiştir. Bu liflerin oldukça yüksek deformasyona uğraması nedeniyle lifsi yapıların pek çoğunun lifin boyuna yönde serbest kaldığı ve lif demeti şeklinde hareket ettiği düşünülmektedir. Bu durumun darbe dayanımını artırmış olabileceği sonucuna varılmıştır.

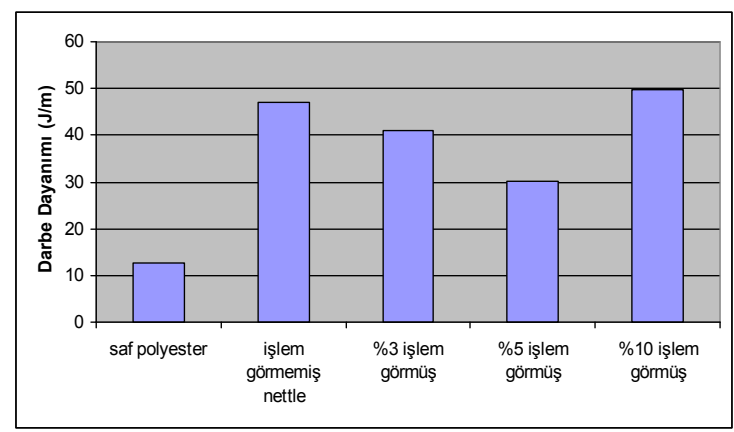

Şekil 8. Kompozit plakaların darbe dayanımı

Araştırma bulguları literatürdeki çalışmalarla karşılaştırılırken ağırlıklı olarak \%30 elyaf takviyesi ve reçinenin polyester olmasına dikkat edilmiştir. Çizelge 2, elde edilen sonuçların içinde mekanik özelliklerin en iyi değerlerini ve literatürden seçilmiş çalışmalarla karşılaştırmaları göstermektedir [35-38]. Bu çalışmalarda matris polyester, takviyeler ise doğal elyaftır. Doğal elyaf takviye oranlarının $\% 25-\% 50$ aralığında olduğu görülmektedir. \%5 1sırgan otu lifli Kompozit; emodülünde sisal ve keten elyafa yakın bir değer göstermiş olup pamuk ve jüt lifinden değer olarak kötüdür. Çekme dayanımında; sisal ve keten dan daha iyi, pamuk ve jütten daha kötü değer göstermiştir. Kopma uzamasında; sisale göre daha çok uzayan bir davranış göstermiştir. 
Çizelge 2. Bu çalı̧̧madaki kompozit malzeme ile literatürden seçilmiş doğal lif takviyeli polyester kompozit malzemelerin mekanik özelliklerinin karşılaştırmalı incelenmesi

\begin{tabular}{|c|c|c|c|c|c|c|c|}
\hline Kompozit & $\begin{array}{l}\text { E-Modül } \\
\text { (MPa) }\end{array}$ & $\begin{array}{l}\text { Çekme } \\
\text { dayanımı } \\
(\mathrm{MPa})\end{array}$ & $\begin{array}{c}\text { Kopma } \\
\text { uzama } \\
(\%)\end{array}$ & $\begin{array}{c}\text { Eğilme } \\
\text { dayanımı } \\
(\mathrm{MPa})\end{array}$ & $\begin{array}{c}\text { Darbe } \\
\text { Izod } \\
\text { dayanımı } \\
(\mathrm{J} / \mathrm{m})\end{array}$ & $\begin{array}{c}\text { Darbe (Izod) } \\
\text { İş } \\
(\mathrm{J})\end{array}$ & Referans \\
\hline Saf polyester & 738,00 & 31,388 & 4,148 & 47,34 & 12,54 & $\mathbf{0 , 0 7 3 8}$ & $\begin{array}{c}\mathrm{Bu} \\
\text { çalışmada }\end{array}$ \\
\hline $\begin{array}{l}\text { Așındırılmamış 1sırganotu } \\
\text { lifi-polyester, } \\
\text { (elyaf oranı \%30) }\end{array}$ & 897,80 & 53,322 & 4,846 & 70,246 & 47,02 & 0,2460 & $\checkmark$ \\
\hline $\begin{array}{l}\% 3 \mathrm{NaOH} \text { ile Aşındırılmış } \\
\text { 1sırganotu lifi-polyester, } \\
\text { (elyaf oranı \%30) }\end{array}$ & 963,40 & 43,362 & 4,178 & 73,716 & 41,03 & 0,2150 & $\checkmark$ \\
\hline $\begin{array}{l}\% 5 \mathrm{NaOH} \text { ile modifiye } \\
\text { 1sirganotu lifi-polyester, } \\
\text { (elyaf oranı } \% 30 \text { ) }\end{array}$ & 1223,20 & 48,696 & 4,006 & 72,141 & 30,28 & 0,2040 & $\checkmark$ \\
\hline $\begin{array}{l}\text { \%10 NaOH ile Așındırılmış } \\
\text { 1sırganotu lifi-polyester, } \\
\text { (elyaf oranı } \% 30 \text { ) }\end{array}$ & 884,83 & 39,876 & 4,05 & 72,144 & 49,78 & 0,2550 & $\checkmark$ \\
\hline $\begin{array}{l}\text { Jüt-Polyester, sicak } \\
\text { kürleme, } \\
\text { (elyaf oranı \%55) }\end{array}$ & $2435 \pm 884$ & $78,15 \pm 7,45$ & $5,04 \pm 0,72$ & & & & {$[35]$} \\
\hline $\begin{array}{l}\text { Sisal-Polyester, } \\
\text { (elyaf oranı } \% 50 \text { ) }\end{array}$ & 1150,00 & 29,66 & 9,52 & 59,570 & & & {$[36]$} \\
\hline $\begin{array}{l}\text { Keten-Polyester, } \\
\text { (elyaf oran1 \% } \% 25 \text { ) }\end{array}$ & 1112,00 & 19,40 & 6,10 & & & & [37] \\
\hline $\begin{array}{l}\text { Pamuk-Polyester, } \\
\text { (elyaf oran1 \%35) }\end{array}$ & 4000,00 & 72,00 & & & & & {$[38]$} \\
\hline
\end{tabular}

\subsection{Kompozitle İlgili SEM Analizi}

Çalı̧̧mada elde edilen kompozit plakalardan test yöntemine uygun olarak alınan numunelerin kesit görüntüleri de incelenmiştir. $\mathrm{Bu}$ görüntülerde $\% 100$ polyester plaka da numune olarak alınmış ve takviye malzemesinin polyester içerisindeki durumu daha iyi analiz edilmeye çalışılmıştır. Kompozit mekanik test numunelerinin SEM görüntüleri üzerinden yorumlar sırasıly verilmiştir. Şekil 9a-b-c-d, çekme testindeki SEM görüntülerinde alkali işlemle liflerin daha çok pürüzlendiği ve matris içinde işlemsiz liflere göre daha fazla kırılıp dağıldığı görülmüştür. İşlemsiz ısırgan otu kompozitte çekme dayanımı diğer örneklere göre daha iyi olduğu görülmüştür. SEM analizinde de kırılmamış daha rijit liflerin çoğunlukta olması bu sonuçla uyumludur. Şekil 10a-b-c-d, üretilen kompozitlerin 3 nokta eğilme testi uygulaması sonrasında alınan SEM görüntülerinde alkali işlemle liflerin reçineye daha iyi yapıştı̆̆ 1 ve eksene dik yükleri karşılamada daha iyi performans sağladığı görülmüştür. Burada SEM analizinde liflerin kırılma yüzeylerindeki durumu görülmektedir. Liflerde eksene dik uygulanan yük altında parçalanmadan kopma şeklinde bir davranış görülmektedir. Bu durum eğme dayanımında lif katkısının yüksek olmasını doğrulamaktadır.

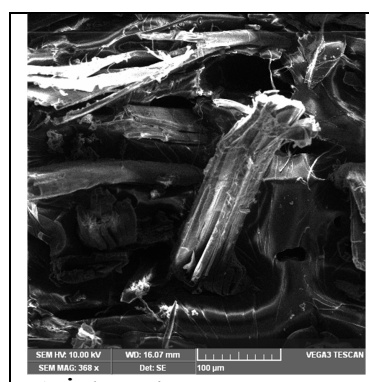

a) İşlemsiz

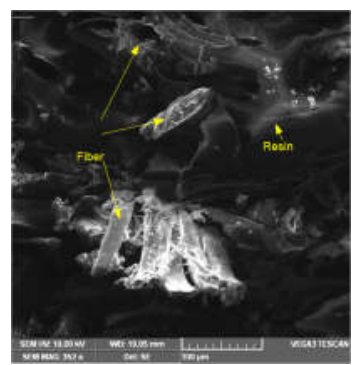

c) $\% 10 \mathrm{NaOH}$ işlemli

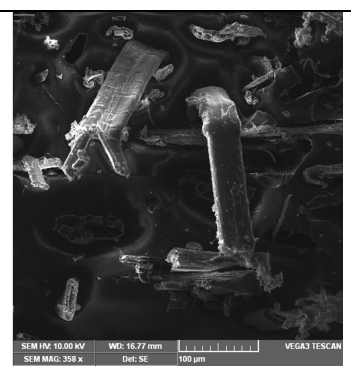

b) $\% 3 \mathrm{NaOH}$ işlemli

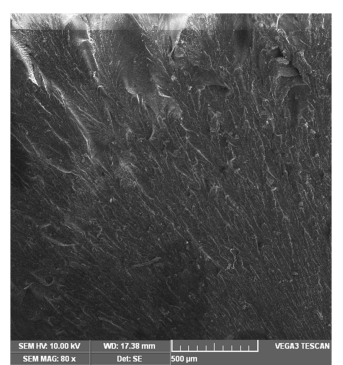

d) Polyester plaka
Şekil 9. Kompozit plakaların çekme testi sonrası SEM görüntüleri 


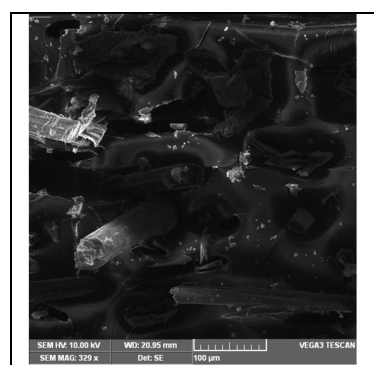

a) İşlemsiz

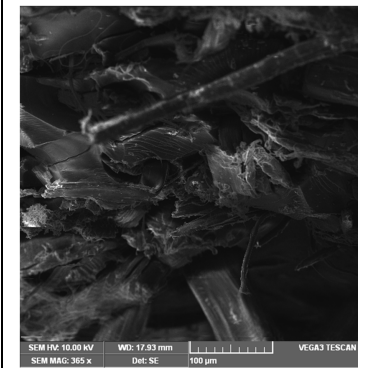

c) $\% 5 \mathrm{NaOH}$ işlemli

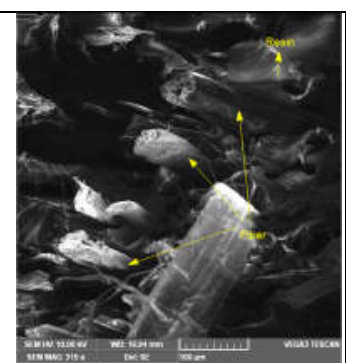

b) $\% 3 \mathrm{NaOH}$ işlemli

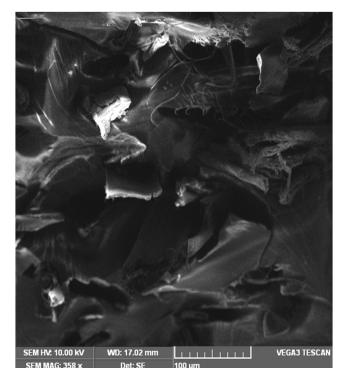

d) $\% 10 \mathrm{NaOH}$ işlemli

Şekil 10. 3 Nokta eğilme test numunelerinin SEM görüntüleri

Şekil 11a-b-c-d'de verilen SEM görüntüleri kırılma yüzeylerindeki durumu göstermektedir. Darbe dayanımı deneyinde lifli üretilen kompozitlerin darbe dayanımı oldukça yüksek çıkmıştır. Darbe yükü, çekicin deney numunesine çarpması seklinde uygulanmaktadır. Kesitte bu şekildeki yüke dayanımda lifsi uzamalar saçaklanmış parçalanmış görüntüler dikkati çekmektedir. Liflerin eksene dik gelen darbe yüküne direnç gösterdikleri genel görünümlerinden anlaşılmaktadır. Parçalanan kesit düz ve parlak olsaydı liflerin direnç göstermediği söylenebilirdi.

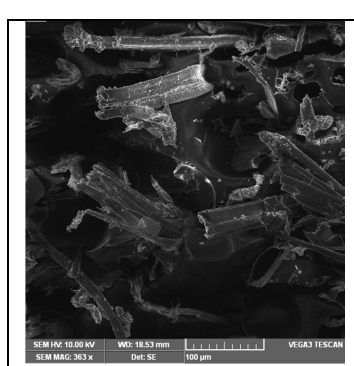

a) İşlemsiz

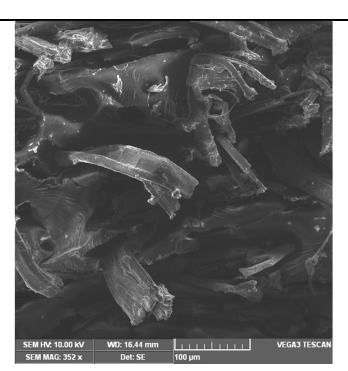

b) $\% 3 \mathrm{NaOH}$ ișlemli

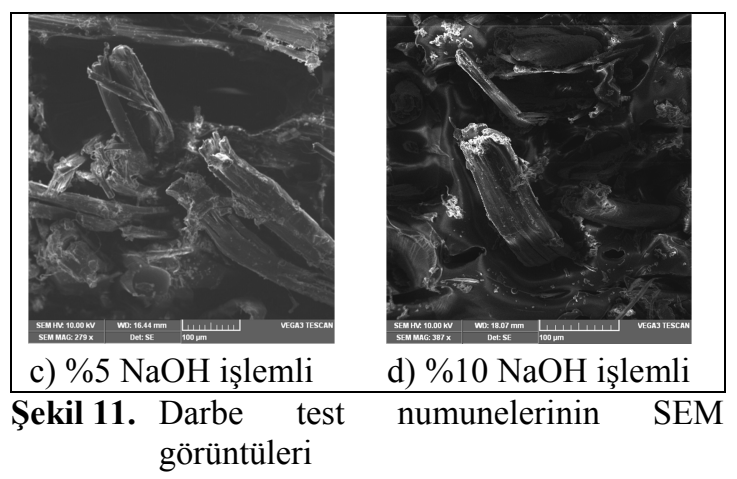

\section{SONUÇ}

$\mathrm{Bu}$ çalışmada 1sırgan otu doğal lifi destekli polyester kompozit plakalar üretilmiştir. Lifler polyester plaka için boynuna yönde ve tarak şeriti halinde yerleştirilmiştir. $\mathrm{Bu}$ durumda üretilen plakanın en iyi mekanik dayanımı darbe dayanımında görülmüştür. Daha sonra eksene dik yüklenen eğilme dayanımının iyi olduğu, en son çekme modülü ve çekme dayanımının geldiği görülmüştür. Takviyenin doğal lif ve kesikli (süreksiz) halde olması nedeniyle çekme dayanımın diğer dayanımlardan daha az çıkması doğal karşılanmıştır. Yine de işlem görmemiş 1sırgan otu lifi destekli olan kompozit plakaların çekme dayanımının $(53,32 \mathrm{MPa})$, saf polyester plakanın çekme dayanımından (31,4 MPa) daha iyi değerde olduğu tespit edilmiştir. Isırgan otu elyafina uygulanan alkali işlemin, kompozitin çekme dayanımını düşürdüğü ancak eğme ve darbe dayanımını iyileştirdiği görülmüştür. Isırgan otu lifinin kompozit malzemelerde takviye olarak kullanılabileceği zaten ucuz olan polyestere $\% 30$ oranındaki ilaveyle bile daha iyi mekanik özellikler kazandırabileceği sonucuna ulaşılmıştır.

\section{TEȘEKKÜR}

Bu çalışma, Çukurova Üniversitesi Rektörlüğü Bilimsel Araştırma Projeleri Birimince desteklenmiştir (Proje kodu: FED-2015-4350). Projenin ön bulguları Romanya'daki $15^{\text {th }}$ World Textile Conference, AUTEX2015'de poster bildiri şeklinde sunulmuştur. 


\section{KAYNAKLAR}

1. Riedel, U., Nickel, J., 1999. Natural Fibre Reinforced Biopolymers as Construction Materials New Discoveries, Die Angewandte Makromolekulare Chemie, 272, 34-40.

2. Arıcasoy, O., 2006. Kompozit Sektör Raporu, İstanbul Ticaret Odası, İstanbul.

3. Mazumdar, S.K., 2002. Composites Manufacturing: Materials, Product, and Process Engineering, CRC Press, New York.

4. Saheb, D.N., Jog, J.P., 1999. Natural Fiber Polymer Composites: A Review, Advances in Polymer Technology, 18(4), 351-363.

5. Li, X., Tabil, L.G., Panigrahi, S., 2007. Chemical Treatments of Natural Fiber for Use in Natural Fiber-Reinforced Composites: A Review, Journal of Polymers and the Environment, 15(1), 25-33.

6. Davies, G.C., Bruce, D.M., 1998. Effect of Environmental Relative Humidity and Damage on the Tensile Properties of Flax and Nettle Fibres, Textile Research Journal, 68(9), 623-629.

7. Vogl, C.R., Hartl, A., 2003. Production and Processing of Organically Grown ${ }^{\circledR}$ ber Nettle (Urtica dioica L.) and its Potential Use in the Natural Textile Industry: A Review, American Journal of Alternative Agriculture, 18(3), 119-128.

8. Summerscales, J., Dissanayake, N.P.J., Virk, A.S., Hall, W., 2010. A Review of Bast Fibres and Their Composites. Part 1 - Fibres as Reinforcements, Composites Part A: Applied Science and Manufacturing, 41(10), 1329-1335.

9. Singh, S.C., Shrestha, R., 1987. Extraction and Chemical Analysis of Himalayan Nettle Fibre, Research and Industry, 32(4), 259-262.

10. Bacci, L., Baronti, S., Predieri, S., di Virgilo, N., 2008. Fiber Yield and Quality of Fiber Nettle (Urtica Dioica L.) Cultivated in Italy, Industrial Crops and Products, 29, 480-484.

11. Bacci, L., Lonardo, S.D., Albanese, L., Mastromei, G., Perito, B., 2010. Effect of Different Extraction Methods on Fiber Quality of Nettle (Urtica dioica L.), Textile Research Journal, 81(8), 827-837.
12. Huang, G., 2005. Nettle (Urtica cannabina L) Fibre, Properties and Spinning Practice, Journal of the Textile Institute, 96(1), 11-15.

13. Bodros, E., Baley, C., 2008. Study of the Tensile Properties of Stinging Nettle Fibres (Urtica Dioica), Materials Letters, 62, 2143-2145.

14. Paukszta, D., Ma Nkowski, J., Kołodziej, J., Szostak, M., 2013. Polypropylene (PP) Composites Reinforced with Stinging Nettle (Utrica dioica L.) Fiber, Journal of Natural Fibers, 10, 147-158.

15. Bajpai, P.K., Meena, D., Vatsa, S., Singh, I., 2013. Tensile Behavior of Nettle Fiber Composites Exposed to Various Environments, Journal of Natural Fibers, 10(3), 244-256.

16. Marila, A.J. 2010. Ms Thesis, Materials and Manufacturing Engineering/Polymer Engineering, MSc Programmes in Engineering Materials Technology (EEIGM)/2000:235, (ISSN 1402-1617/ISRN LTU-EX--00/235--SE /NR 2000:235), Lulea University of Tecchnology, Sweden, http://epubl.luth.se/ 1402-1617/2000/235/index-en.html (Erişim: $11^{\text {th }}$ Dec 2015)

17. Fischer, H., Werwein, E., Graupner, N., 2012. Nettle Fibre (Urtica dioica L.) Reinforced Poly (Lactic Acid): A First Approach, Journal of Composite Materials, 46(24), 3077-3087.

18. Bajpai, P.K., Singh, I., Madaan, J., 2012. Comparative Studies of Mechanical and Morphological Properties of Polylactic Acid and Polypropylene Based Natural Fiber Composites, Journal of Reinforced Plastics and Composites, 31(24), 1712-1724.

19. Gassan, J., Bledzki, A.K., 1999. Possibilities for Improving the Mechanical Properties of Jute/Epoxy Composites by Alkali Treatment of Fibres, Composites Science and Technology, 59(9), 1303-1309.

20. Prasad, S.V., Pavithan, C., Rohatgi, P.K., 1983. Alkali Treatment of Coir Fibres for CoirPolyester Composites, Journal Material Science, 18, 1443-1454.

21. Sydenstricker, T.H.D., Mochnaz, S., Amico, S.C., 2003. Pull-Out and Other Evaluations in Sisal Reinforced Polyester Biocomposites, Polymer Testing, 22, 375-380. 
22. Ray, D., Sarkar, B.K., Rana, A.K., Bose, N.R., 2001. Effect of Alkali Treated Jute Fibres on Composite Properties, Bulletin of Materials Science, 24(2), 129-135.

23. Jacob, M., Thomas, S., Varughese, K.T., 2004. Mechanical Properties of Sisal/Oil Palm Hybrid Fiber Reinforced Natural Rubber Composites, Composites Science and Technology, 64, 955-965.

24. Mishra, S., Mohanty, A.K., Drzal, L.T., Misra, M., Parija, S., Nayak, S.K., Tipathy, S.S., 2003. Studies on Mechanical Performance of Biofibre/Glass Reinforced Polyester Hybrid Composites, Composites Science and Technology, 63, 1377-1385.

25. Liu, X.Y., Dai, G.C., 2007. Surface Modification and Micromechanical Properties of Jute Fiber Mat Reinforced Polypropylene Composites, Express Polymer Letters, 1(5), 299-307.

26. Van De Weyenberg, I., Ivens, J., De Coster, A., Kino, B., Baetens, E., Verpoest, I., 2003. Influence of Processing and Chemical Treatment of Flax Fibres on Their Composites, Composites Science and Technology, 63, 1241-1246.

27. Seki, Y., 2009. Innovative Multifunctional Siloxane Treatment of Jute Fiber Surface and Its Effect on the Mechanical Properties of Jute/Thermoset Composites, Materials Science and Engineering A., 508, 247-252.

28. Ray, D., Sarkar, B.K., Rana, A.K., 2002. Fracture Behavior of Vinylester Resin Matrix Composites Reinforced with Alkali Treated Jute Fibers, Journal of Applied Polymer Science, 85, 2588-2593.

29. Razera, I.A.T., Frollini, E., 2004. Composites Based on Jute Fibers and Phenolic Matrices: Properties of Fibers and Composites, Journal of Applied Polymer Science, 91, 1077-1085.

30. Cao, Y., Shibata, S., Fukumoto, I., 2006. Mechanical Properties of Biodegradable Composites Reinforced with Bagasse Fiber Before and After Alkali Treatments, Composites: Part A, 37(3), 423-429.

31. Van De Weyenberg, I., Chi Truong, T., Vangrimde, B., Verpoest, I., 2006. Improving the Properties of UD Flax Fibre Reinforced Composites by Applying an Alkaline Fibre
Treatment, Composites: Part A, 37, 1368-1376.

32. Herrera-Franco, P.J., Valadez-Gonzalez, A., 2005. A Study of the Mechanical Properties of Short Natural-Fiber Reinforced Composites, Composites: Part B, 36, 597-608.

33. Cao, Y., Shibata, S., Fukumoto, I., 2006. Mechanical Properties of Biodegradable Composites Reinforced with Bagasse Fibre Before and After Alkali Treatments, Composites Part A, 37, 423-429.

34. Karaduman, Y., Gokcan, D., Onal, L., 2013. Effect of Enzymatic Pre-Treatment on the Mechanical Properties of Jute Fiber-Reinforced Polyester Composites, Journal of Composite Materials, 47(10), 1293-1302.

35. Dash, B.N., Rana, A.K., Mishra, H.K., Nayak, S.K., Mishra, S.C., Tripathy, S.S., 1999. Novel, Low-cost Jute-polyester Composites, Part 1: Processing, Mechanical Properties and SEM Analysis. Polymer Composites, 20(7), 62-71.

36. Singh, B., Gupta, M., Verma, M., 1996. Influence of Fiber Surface Treatment on the Properties of Sisal-polyester Composites. Polymer Composites, 17(6), 910-918.

37. Baiardo, M., Zini, E., Scandola, M., 2004. Flax Fibre-polyester Composites, Composites: Part A, 35, 703-710.

38. Gohil, P.P., Shaikh, A.A., 2010. Experimental Investigation and Micro Mechanics Assessment for Longitudinal Elastic Modulus in Unidirectional Cotton-polyester Composites. International Journal of Engineering and Technology, 2(2), 111-118. 
